\title{
COMMON AORTO-PULMONARY TRUNK: A RARE CONGENITAL DEFECT
}

\author{
BY \\ C. W. CURTIS BAIN AND JOHN PARKINSON \\ Received February 4, 1943
}

A lad of eighteen was first seen on May 18, 1942. A congenital heart lesion had been diagnosed when he was a few weeks old, and though he was not then cyanosed at rest, he soon became blue and breathless on exertion, especially in cold weather. He had scarlet fever at the age of ten, but never rheumatism in any form. At the age of twelve, he was too breathless for any but short walks. He was unfit to play any games at school. A change had taken place six months before (October, 1941) when cyanosis became permanent and the dyspnœa more distressing. There had been neither orthopnœa nor œdema; he had never fainted, and he had not lost weight. Pain had started during these last months of increased dyspnœa, and now constituted the greater complaint, though he was no complainer. On exertion it began in the left arm and if severe it affected the right. It was felt across the chest, especially on the left, but not in the back. Rest, especially if with warmth, relieved it, yet it might last 10 to 20 minutes once evoked by exertion, for it never began at rest. Palpitation was felt on emotion or exertion. There was a slight occasional cough.

Examination.-He was a pleasant and fairly well-developed youth, with some cyanosis of the skin and moderate clubbing of the fingers and toes. The pulse was 70-80, and regular. The blood pressure was $125 / 100$. A heaving apex beat was felt in the fifth space, two inches outside the nipple line. A long diastolic thrill was felt widely in the apical region, yet there was no thrill at the base. The first sound was snapping internal to the apex, and a thundering diastolic murmur was heard over the whole apical region, up to the fourth rib, though loudest internal to the apex. At the base the murmur was less loud; the basal second sound was just audible. There were no abnormal signs in the lungs or abdomen.

The electrocardiogram (Fig. 1A) showed a small $\mathrm{R}$ and a large $\mathrm{S}$ in all leads, and an isoelectric T in lead I. Two months later, three days before his death on July 18, 1942, T I was inverted (Fig. 1B).

Cardioscopy showed enlargement of the heart, mainly to the right, but with a single big rounded prominence on the left, in the region of the pulmonary artery and extending upwards to embrace the aortic area so that no aortic knob was visible. The right pulmonary artery was, however, not enlarged. In the right (I) oblique position, a barium swallow showed a combined aorto-pulmonary impression and no particular displacement of the left auricle. Radiographs by Major Peter Kerley are shown in Fig. 2 and 3.

Course. A tentative diagnosis was made of patent ductus arteriosus with aneurysmal dilatation of the pulmonary artery, presumably combined with some other defect. This presumption seemed to preclude operation when this was considered because of the deterioration in his condition as already described. The physical signs by July 14, 1942 had altered as follows. Cyanosis was extreme, though he was not, even now, breathless at rest and could walk slowly in the street. The murmur had become more continuous, but it had not the characteristic variation of a ductus murmur. The liver was palpable and pulsating, but there was no œdema.

Four days later, in the evening black-out, he failed to get a taxi and took the underground 
tube to return to his friends in their suburban home. At that station the escalator had ceased working, so he was forced to climb the stairs from the station level to the surface, whereupon he died suddenly. We were allowed to perform a post-mortem examination.
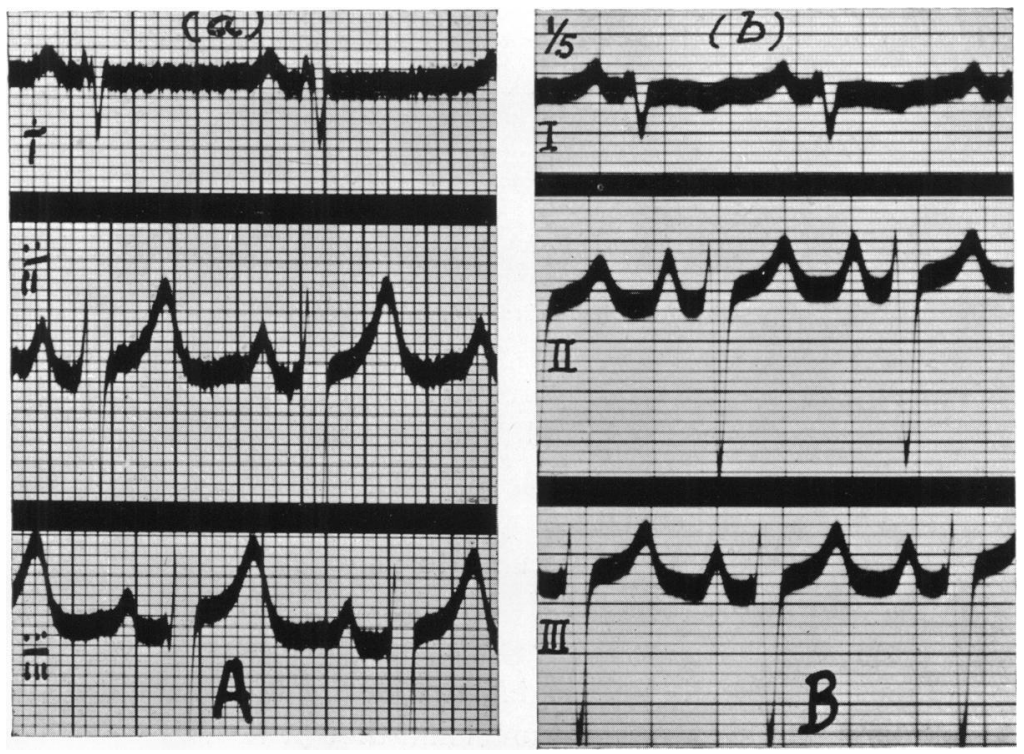

Fig. 1.-Electrocardiograms, (A) taken on May 18, and (B) taken two months later, July 15, 1942.

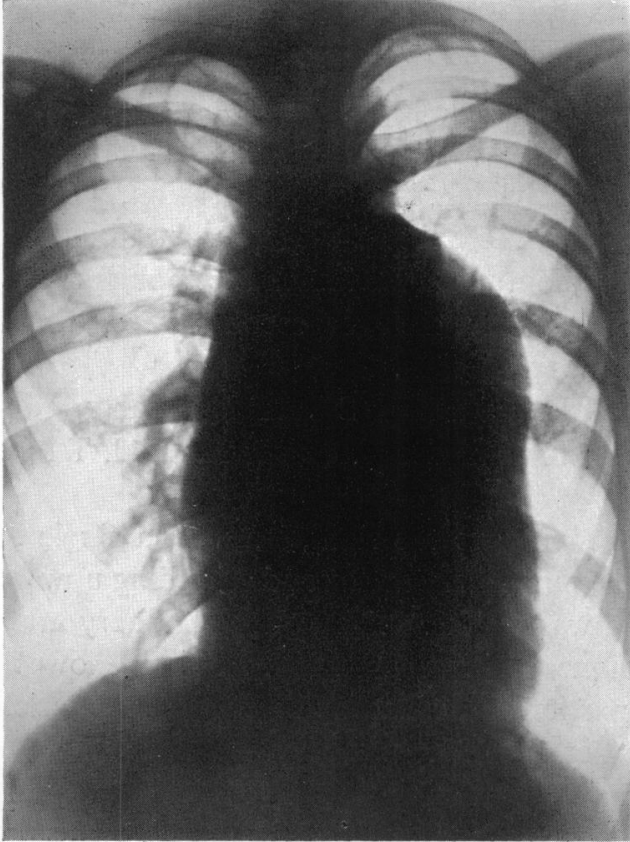

FIG. 2.-Radiograph (anterior view) showing aortopulmonary sac.

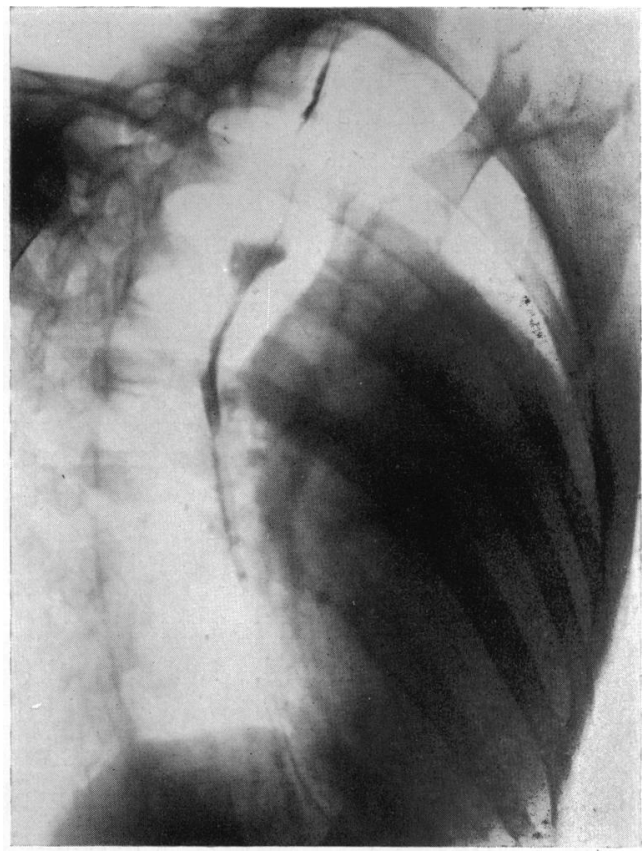

FIG. 3.-Radiograph (right (I) oblique view), with barium in the œsophagus.

A fairly nourished man of average build, with no œdema.

The pericardium is normal and the sac contains about 7 ounces of clear fluid.

The heart on external examination appears greatly enlarged, chiefly owing to the size 

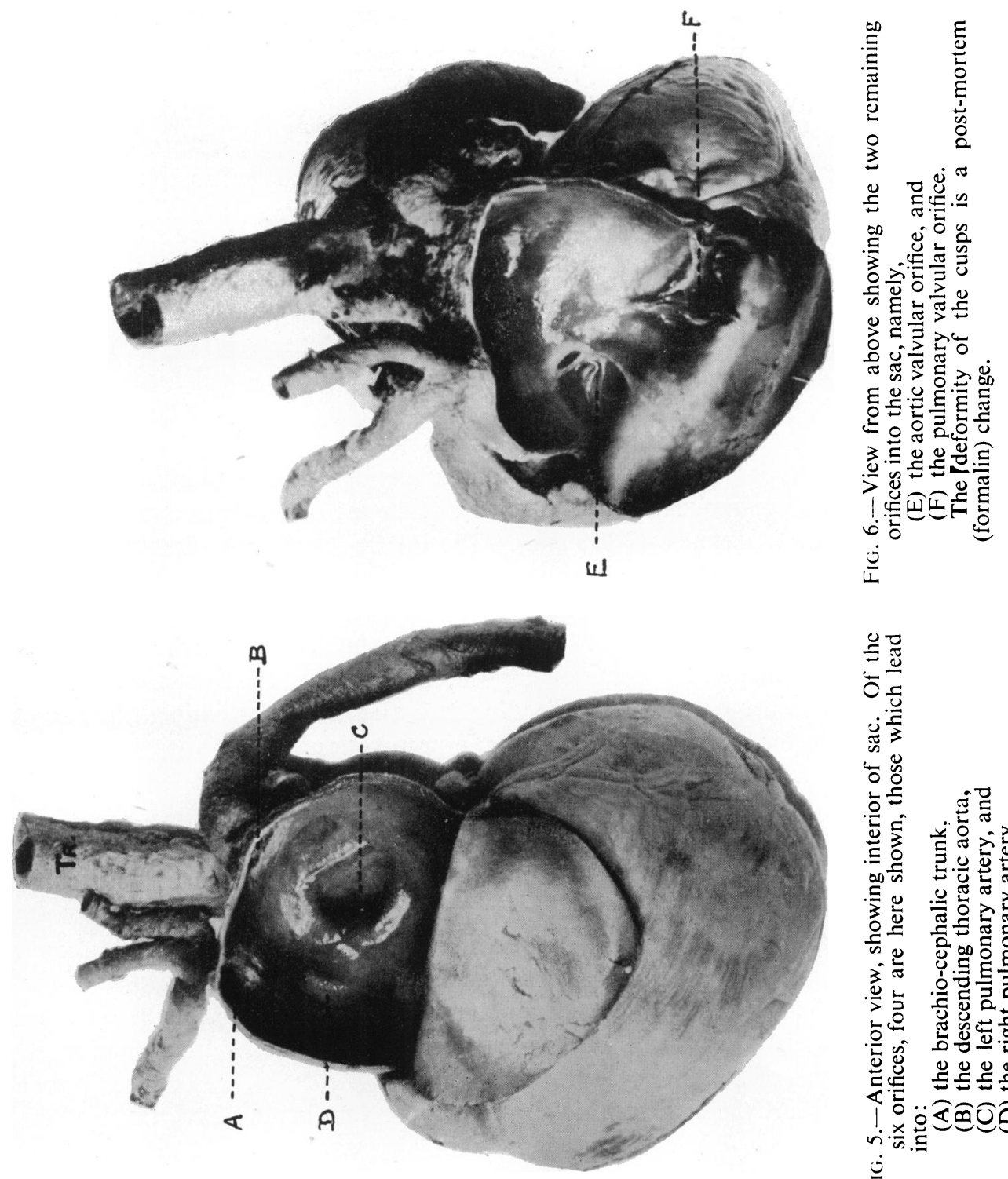

它
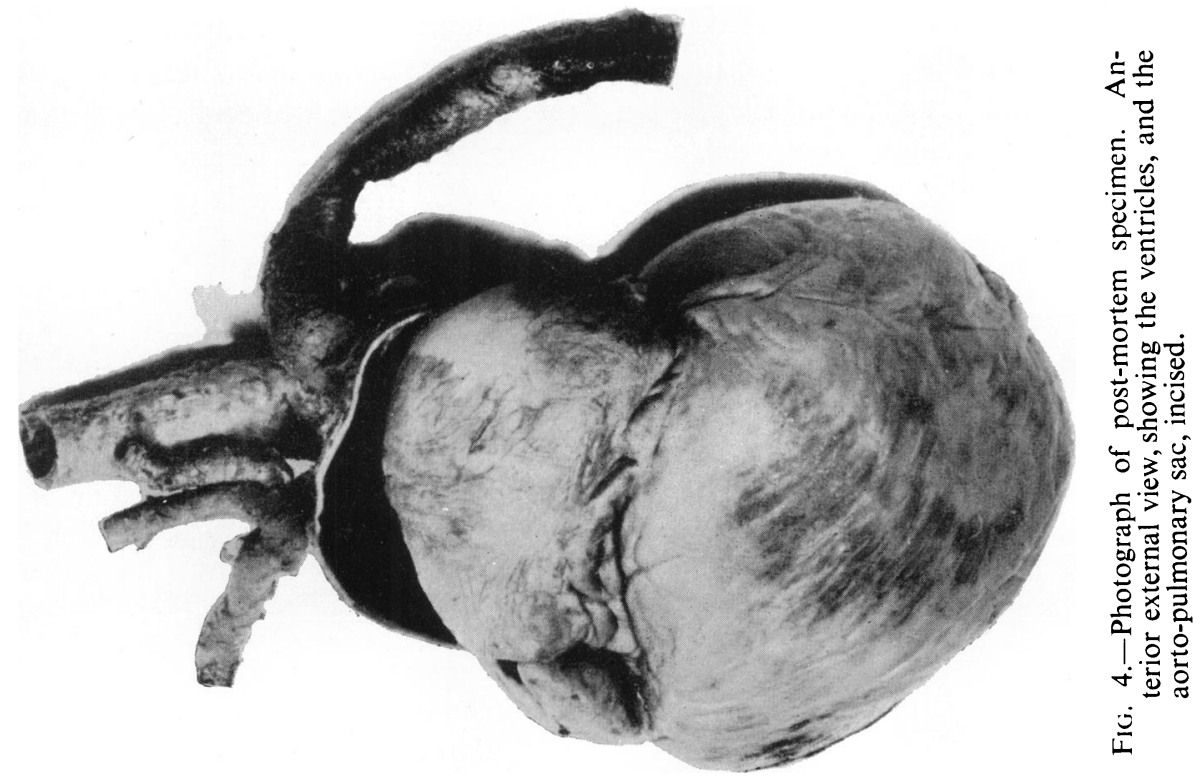

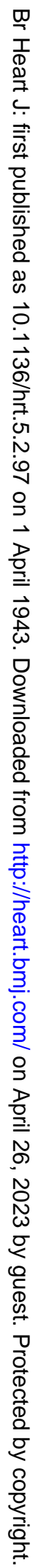


of the right ventricle, which forms most of the anterior surface of the ventricles and most of the apex, while the left ventricle forms a small part of the left border and reaches the apex. The conus of the right ventricle seems prominent and the left auricular appendage is well hidden. The right auricular appendage is easily visible on the right.

Above the ventricles is seen a single ovoid aorto-pulmonary sac, measuring $8 \times 7 \times 6 \mathrm{~cm}$. after fixation in formalin (Fig. 4). Externally it looks as if composed of the ascending aorta and a (larger) dilated pulmonary artery. Between these two elements a small vein runs downwards on the anterior outer surface of the sac to the base of the ventricles. The right or aortic element is yellowish-but not so yellow as a normal aorta-and forms about onethird of the total sac as seen externally. The pulmonary artery element is bluish, and forms about two-thirds of the sac. The superior vena cava is normal.

On incising the sac, it proves to be single and undivided, with nothing to suggest any division into aortic and pulmonary stems. The wall of the sac is similar to that of an average aorta and is uniform in thickness $(0.125 \mathrm{~cm}$.). The internal surface is smooth throughout, and there is no ante-mortem clot.

Opening into the sac from above downwards, are six apertures (Fig. 5 and 6).

(A) A rounded orifice leading to a common brachio-cephalic trunk which after a course of $1 \mathrm{~cm}$. divides into innominate, left common carotid, and left subclavian arteries.

(B) An oval and rather narrow orifice leading into a smallish descending thoracic aorta with an external diameter of $1.7 \mathrm{~cm}$. in the formalin preparation.

(C) A slightly-funnelled orifice of the left pulmonary artery.

(D) A funnelled orifice of the right pulmonary artery.

(E) The aortic valvular orifice, leading from the left ventricle into the base of the sac. The aortic orifice and cusps are normal, with normally situated orifices of both coronary arteries.

(F) The pulmonary valvular orifice $(2 \cdot 3 \mathrm{~cm}$. diam. after fixation in formalin), leading from the right ventricle into the base of the sac, and separated from the aortic valvular orifice $(E)$ by a wide bridge $(1.5 \mathrm{~cm}$. broad) of the aorto-pulmonary saccular wall at its base (or caudal extremity). There is slight cord-like thickening of the middle of the free margins of the otherwise normal cusps of the pulmonary valve.

On opening the heart the right ventricle is seen to be very greatly hypertrophied $(1 \mathrm{~cm}$. thick) and slightly dilated. The right auricle is slightly hypertrophied and dilated. There is no dilatation or hypertrophy of left ventricle $(1.2 \mathrm{~cm}$. thick) or left auricle. No ante-mortem thrombus is found in the heart or great vessels. The mitral and tricuspid valves are normal.

The pleura are normal, without adhesions, and each sac contains a few ounces of clear fluid. The lungs are moderately congested. The brain and the cerebral and cranial vessels are normal. The liver is slightly enlarged, very firm and congested. There is great congestion of the hepatic veins, and of the inferior vena cava. The spleen is of normal size, firm, and congested.

\section{SUMMARY}

A common aorto-pulmonary trunk, as an isolated gross congenital malformation, was found at death in a man of eighteen years, who had always been cyanosed and breathless. Electrocardiograms, radiographs, and pathological details are recorded. The malformation cannot be classified as persistent truncus arteriosus, because there was neither a defect of the interventricular septum, nor any abnormality of the aortic and pulmonary valves.

We wish to thank Dr. J. W. Brown for his valued opinion, Major William Phillips, R.A.M.C., for clinical help, and Major Peter Kerley, R.A.M.C., for the radiographic investigation. To Dr. W. W. Woods, Assistant Director of the Pathological Institute of the London Hospital, we are much indebted for amplifying and completing the necropsy report. 